\section{IJIKMMENA}

2,2

\section{3}

\title{
NEOLIBERALISM IN EDUCATION: HOW PMS UNDERMINED EMPLOYEE MOTIVATION AND ACADEMIC FREEDOM AT THE
UNIVERSITY OF BOTSWANA
}

\author{
Motsomi Ndala Marobela' \\ and \\ Kerstin Andrae-Marobela ${ }^{2}$ \\ University of Botswana, Botswana
}

\begin{abstract}
Purpose: This paper examines the implementation of Performance Management System (PMS) at the University of Botswana and its impact on worker's motivation. PMS was inspired by the New Public Management (NPM) doctrine emphasising efficiency.

Design/methodology/approach: An exploratory methodology was used, combined with critical realism explaining the dynamics of forced change in relation to academic staff performance. Interviews were conducted to solicit views of staff in four different departments.

Findings: Our findings show that PMS has failed to enhance performance and motivate staff. Instead of supporting the university's vision of promoting excellence and academic freedom, it created an environment of punishment, fear and demotivation.

Originality/value: Change involving performance management is complex and contested. Established PMS models in the private sector might fail in an academic setting, as different factors shape staff performance, and academic freedom is imperative.
\end{abstract}

International Journal of Innovation and Knowledge Management in Middle East \& North Africa Vol. 2 No. 2, 2013

Copyright @ 2013 WASD
Keywords: Education, Academic freedom, Staff performance, NPM, Forced change

${ }^{1}$ Dr Motsomi Ndala Marobela, Department of Management, University of Botswana, Gaborone, BOTSWANA, Email:marobela@mopipi.ub.bw

${ }^{2}$ Dr Kerstin Andrae-Marobela, Department of Biological Sciences, University of Botswana, Gaborone, BOTSWANA, Email: marobelak@mopipi.ub.bw 


\section{INTRODUCTION}

Managing employee performance is a central concern for any organisation. Performance Management System (PMS) is a strategic management concept designed to enhance organizational efficiency (Armstrong, 2009). It seeks to integrate personal goals and objectives to that of the organization. A process is set out where performance targets for employees are established, reviewed and rewarded according to the achievement of set goals. Conversely, corrective measures are used to address poor performers. In terms of its theoretical framework we locate the sociology of PMS to the new public management associating PMS with the concept of new managerialism (Pollitt, 1993) in the public services. Both of these theories form the basis of neoliberal ideology (Harvey, 2005), a global doctrine which is changing the nature and form of the public sector (Narsiah, 2002) and pushing for market efficiency and privatisation of public services. In this context neoliberalism is linked to changing employment relationships and management practices.

Universities have not escaped the influence of neoliberal reforms. Across the world universities have sought to achieve their missions of excellence by adopting performance management (Callinicos, 2005; Dator, 2005) including the University of Botswana.

This study investigates the perceptions of academic staff on the implementation of PMS at the University of Botswana. It probes whether or not the objectives of increasing efficiency, motivation and increased measurable output of staff has been achieved.

\section{PHILOSOPHICAL FRAMEWORK AND METHODOLOGY}

Our philosophical paradigm comes from critical realism (Archer et al., 1998), which emphasizes context-based research. A critical realist ontological perspective does not necessarily identify high quality research as research based on large samples. Small samples using a purposive sampling procedure are also valid as they focus on a smaller knowledgeable group affected and experiencing change. A qualitative exploratory survey methodology was used to solicit views of academic staff on PMS. Fortyone (41) employees at the University of Botswana, from one department of the Faculty of Science and three departments from the Faculty of Business were interviewed in 2010 and 2011 using a semi-structured questionnaire on how PMS affected the routine of academic work. 


\section{RESULTS}

\section{2,2}

\section{Background of interviewees}

$63 \%$ of respondents $(\mathrm{N}=41)$ were male and $37 \%$ were female academic staff, of which the majority (56\%) had a doctoral degree, $42 \%$ possessed a Master's degree and 2\% had obtained a Bachelor's degree. Close to half of the interviewees (46\%) occupied a Senior Lecturer position, 39\% a Lecturer position, while only $7 \%$ were professors. The low percentage of professors represents the structure of the two departmental establishments and was not a consequence of interview bias. The years of service varied over a considerable range with $29 \%$ of respondents employed for less than six years, with 27\% having been employed between 6 and 10 years, $15 \%$ between $11-15$ years, $20 \%$ between 16 and 20 years and $10 \%$ over 20 years. During their years of service, academic staff had most likely seen different systems of evaluation, which makes the group of interviewees reasonably knowledgeable.

\section{What is PMS and how was it introduced at the University of Botswana?}

We first wanted to establish how employees would explain PMS. Three quarters of respondents $(75 \%, \mathrm{~N}=40)$ explained PMS as a system to manage/monitor performance where rewards are linked to the actual performance. $7.5 \%$ of respondents saw PMS as a system to improve efficiency and motivation, while $5 \%$ perceived it simply as a control instrument. One employee emphasized that PMS makes work/ performance more objective. However, 10\% of employees interviewed could not actually explain what PMS is. As PMS was introduced as a new system, we were interested in whether employees felt fully informed on why PMS was introduced at the University of Botswana. Over half of the employees $(58 \%, \mathrm{~N}=39)$ stated that they were not informed at all, while $21 \%$ said they felt informed. The same proportion of employees explained that there were attempts from the university management to inform the staff, but that management did not consider the staff's opinion. One interviewee gave an example:

They invited us to a workshop which was rather a public lecture. A colleague said during that workshop that it is wrong to see students as 'clients', as students are rather 'raw material' which still develops. But such concerns were never taken into consideration 
Given a general background of a perceived lack of information amongst staff, we then wanted to know why, in the opinion of the staff, PMS was introduced at the university (Table 1).

Most interviewees placed the objectives of PMS in a framework that sought to improve motivation and efficiency, including the alignment of individual goals to the university goals and to make evaluation of performance more objective. On the other hand, many respondents answered the question with substantial criticism, stating that PMS was simply copied from government structures. Corresponding to the general feeling of non-information about PMS, a number of interviewees also stated that they did not know at all why PMS was introduced.

\section{Is PMS an adequate tool to measure performance in an academic setting?}

We then wanted to characterize the concrete experiences of academic staff, namely whether PMS is perceived as a reasonable tool to measure performance. More than half of the interviewees $(54 \%, \mathrm{~N}=41)$ denied this, while $32 \%$ agreed. $15 \%$ explained that in some ways PMS is useful to evaluate performance, while in others it is not.

Most interviewees agreeing to PMS as a reasonable tool to measure performance emphasized that "measurable objectives" are suitable to assess performance by eliminating manipulation and favouritism, by providing focus and setting clear targets, and by encouraging selfmanagement and accountability in a framework in which one "is forced to perform".

The opinions on the difficulties with PMS are summarized in Table 2.

\begin{tabular}{|c|c|}
\hline & Frequency \\
\hline $\begin{array}{l}\text { Linking rewards to performance in order to improve motivation and } \\
\text { efficiency and quality output }\end{array}$ & 13 \\
\hline To make evaluation more objective & 7 \\
\hline Copied from government & 6 \\
\hline I have no idea & 5 \\
\hline To align individual goals to the goal of the university & 4 \\
\hline To increase control over staff & 4 \\
\hline Management just wanted something new & 3 \\
\hline
\end{tabular}

Table I. The opinion of academic staff on why PMS was introduced at the University of Botswana 
IJIKMMENA

2,2

177

Many respondents felt that academic work is difficult to standardize and to put into "measurable objectives". The following statements illustrate this concern:

When it comes to ongoing research it is not clearly defined what ongoing research is. It can be much or less. It can be ongoing for 10 years or for one year. Also publication is not something you can do every year. Science is not predictable.

All research and teaching is difficult to standardize. There are different class sizes, teaching methods are different, some publications take longer. It is just putting people under pressure. You can't apply the same criteria on all people.

Some contextualized performance measuring and related it to a necessary performance environment, as an employee explained:

In my view the working conditions should be right first. You can't have assessment tools before you even have the right tools to do your work.

Other particularly bemoaned the fact that the Head of Department is the main assessor. They explained:

Just one person does not have a broad knowledge. How can that person asses all?

\section{MOTIVATION, COLLABORATION AND QUALITY OUTPUT}

As the majority of interviewees linked the introduction of PMS to the aim of improving efficiency, quality output and motivation, we probed

\begin{tabular}{lc}
\hline & Frequency \\
\hline Academic work is difficult to standardize & 18 \\
Tools cannot work if the respective performance environment does & 4 \\
not match & 3 \\
Open to manipulation & 3 \\
Highly subjective & 2 \\
Inconsistent & 1 \\
Just control instrument &
\end{tabular}

Table 2.

The difficulties with PMS as a tool to measure performance 
how employees would consider the effect of PMS on these variables in their routine academic work. When asked whether PMS promoted collaboration between colleagues, only 13\% $(\mathrm{N}=39)$ of interviewees agreed, stating that it does so by defining roles in the research process and forcing collaborations by the pressure to publish. $23 \%$ of employees felt that PMS has no influence on collaborative efforts, while the same proportion stated that it is difficult to judge. More than a third of respondents (38\%) were of the view that PMS actually prevents cooperation. The following statements reflected the sentiments exemplary:

There is no scoring system for collaborations in PMS. There is a big contradiction here: everywhere research is encouraged to be collaborative and interdisciplinary, but you are scored individually. For example, in relation to publications PMS discourages multiple authorships, because you get more scores if you publish alone. Some say 'I do it myself' only to get the full scores. That is also de-motivating.

When asked whether PMS increases the efficiency of output in research and/or teaching, 29\% ( $\mathrm{N}=38)$ agreed - stating that PMS forces you to conduct good research and teaching and pushes output (10/17), while others perceived defined targets as positive $(7 / 17) .16 \%(\mathrm{~N}=38)$ stated that PMS partly increases efficiency, but partly not, explaining that in one respect, "to have a system that defines your targets is good, but on the other hand the quality in fulfilling the targets is not necessarily there".

Over half of the interviewees were of the opinion that PMS does not contribute to increasing the efficiency of output. The reasons for this are summarized in Table 3.

\begin{tabular}{lc}
\hline & Frequency \\
\hline Decreases the quality of output & 9 \\
Output is driven by factors other than PMS & 5 \\
Discourages collaborative research & 3 \\
Promotes low achievement & 3 \\
Does not work for teaching & 2 \\
Control and fear affects output negatively & 2 \\
Has no real effect & 1 \\
\hline $\mathrm{N}=38$ &
\end{tabular}

Table 3.

Reasons why PMS does not improve efficiency of output 
IJIKMMENA

2,2

179

Interestingly, the majority of responses bemoaned the decrease of quality of output. "Because you are under pressure the quality of your output decreases. You are tempted to publish in lower ranking journals with preliminary results instead of taking time to do more complete research and publish in a good journal", explained one employee. Others emphasized that other factors, such as reviews of papers, deadlines for grant applications and projects, and collaborative efforts drive output. Three interviewees directly linked PMS with the promotion of low, not high, achievement:

If you state as your target to publish five papers and in the end you publish two you get a score of $40 \%$ achievement. If a colleague intends to publish one paper and he or she publishes it he/she obtains 100\% achievement. What PMS does is that in the end you aim low. You achieve low, but you end up as a high achiever.

Finally, the question of whether PMS improves the motivation of academics in a university setting proved to solicit the most revealing responses. Close to half of the employees $(46 \%, \mathrm{~N}=41)$ stated that PMS has not increased their motivation to work. Additionally, a quarter of all interviewees (25\%) explained that PMS had actually demotivated them, while further 5\% saw PMS as motivating by pressure. Only 15\% felt that PMS contributed to a better motivation, while 7\% stated that PMS has partly motivated, but also partly demotivated them in their academic work. The following reasons for demotivation are instructive (Table 4).

The climate of control, pressure and fear caused by the PMS regime was seen as the most prominent hindrance to work motivation. One respondent lamented:

PMS demotivates me because I feel degraded as an academic who was hired on the basis of a proven qualification. I am treated like someone who is in principle lazy and cannot be trusted. One cannot work in an

Table 4.

Perceptions on why PMS has not increased work motivation

\begin{tabular}{lc}
\hline & Frequency \\
\hline Climate of control/pressure/fear/mistrust & 8 \\
Other factors influence my motivation & 4 \\
Implementation is flawed & 4 \\
We don't own PMS and don't understand it & 4 \\
Constitutes another burden & 4 \\
\hline $\mathrm{N}=24$ &
\end{tabular}


environment where you are assessed for every step you take. It kills inspiration and the willingness to try unconventional ways in research and teaching.

\section{Is PMS relevant in an academic setting?}

As stated above, PMS was perceived by many respondents as copied from government structures. We therefore wanted to know from university employees whether they would consider PMS as relevant in an academic environment. Only 13\% ( $=38)$ of employees felt that PMS is relevant because it equips employees with planning skills. Further, $11 \%$ stated that PMS might be relevant if it could be applied properly. Strikingly, $71 \%$ of interviewees $(\mathrm{N}=38)$ stated that they do not consider PMS as relevant. Probing the reasons for this opinion revealed two main issues, which confirmed the sentiments mentioned earlier on, namely the fact that firstly, academic work has a different dynamic which is not captured by PMS tools, and secondly that academic work cannot be standardized and quantified. The latter point is illustrated by the following statement:

Implementation of PMS is like working in a factory. But as academics we are not working on an assembly line to produce ten good students like cars. Academics do not necessarily produce quantifiable output

\section{CONSULTATION, EVALUATION AND REWARD}

We finally wanted to know whether employees are satisfied with the reward system and the consultative process during the evaluation process. Addressing the latter issue, only $17 \%$ of respondents $(\mathrm{N}=36)$ felt that they are reasonably consulted, while a large majority $(83 \%)$ denied adequate consultation and were consequently not satisfied at all with how the PMS evaluation was conducted. More than half of the employees $(55 \%, \mathrm{~N}=29)$ who indicated their dissatisfaction with PMS evaluation and consultation, expressed their concern about a "highly subjective" evaluation process, which is based on "top-down decisions" where the Head of Department has "too much power". Because of these perceived flaws, consequently, employees were also not satisfied with the reward system $(81 \%, \mathrm{~N}=32)$. The main concerns expressed here were threefold: employees felt that the reward system is flawed because the standardization/evaluation is flawed; rewards are based on un-transparent top-down decisions and finally, most respondents stated that they "don't get the rewards according to performance". 
Although many of interviewees felt ill-informed on why PMS has been introduced, many associated PMS with a tool to manage and evaluate performance with the aim of increasing efficiency, motivation and quality output in the workplace. This is indeed in agreement with the objectives of PMS regimes introduced elsewhere, such as in the private sector (Longenecker, Gioia and Sims, 1987) and in government (Osborne and Gaebler, 1992; van Dooren and Thijs, 2010).

\section{Motivation by pressure - efficiency by fear}

Our findings indicate that nearly all objectives have not been met by the introduction of PMS. Instead of increasing motivation, a considerable number of employees felt de-motivated and suffering under a climate of fear, pressure and mistrust in the workplace.

Although academic work, be it research or teaching, is characterized by social interaction, PMS was largely perceived as preventing collaborative efforts and promoting individualism and competition, which are hallmarks of neoliberalism. This, in turn, led to the opposite of what PMS anticipated achieving: the promotion of efficiency and quality output. These findings are in agreement with a case study conducted at three universities in South-Africa, which concluded that "that typical business approaches to performance management would not work in higher education" (Mapesela and Strydom, 2005).

\section{Targets and academic freedom: "Your goals are somebody else's"}

Academic freedom was always seen as a hallmark of universities: an environment where one is encouraged in critical thinking and where new, creative and innovative ways to better understand interaction with nature and society are promoted. This has profoundly changed with the corporatization of universities as a consequence of the neoliberal doctrine. Although in general, good planning, achieving goals and being efficient are positive attributes and were, by some employees, seen as the positive aspects of PMS in this study, it matters who sets the goals and targets and who draws the plans. The generally distrustful attitude towards academic staff underlying PMS, as it was noted by one interviewee, confirmed the previously described "ambiguous attitude towards expertise and professionals (...) [where] on the one hand, trust in professionalism is vital in an increasingly complex society. On the 
other hand we are reluctant to grant this trust and hence we fall back on control and audit" (van Dooren and Thijs, 2010).

One interviewee beautifully describes how PMS contributes to a profound alienation of one's own academic work, which was previously reported to be a consequence of neoliberalism (Mather, Worral and Seifert, 2009):

With PMS you end up being haphazardous on what you achieve. Your goals are not your goals anymore, they are somebody else's.

Instead of exercising academic freedom and research processes, academics are forced to increase target-defined productivity rates in the form of quantifiable "outputs", which might not be the ones of their own choosing. This points towards one of the generalized paradoxes of PMS, that "not everything that counts can be counted, and not everything that can be counted counts" (Albert Einstein, quoted in van Dooren and Thijs, 2010).

\section{CONCLUSION}

In this paper, we investigated the perception of the application of the performance management system (PMS) concept in higher education at the University of Botswana. Rather than creating an environment where work is enjoyed, knowledge harnessed and motivation promoted, PMS has been perceived as a top-down transformation creating an atmosphere of pressure, fear and demotivation. Following change of leadership at the University of Botswana, this year, PMS was abolished, which has been met with a sigh of relief by the academic staff who resented control, needless procedure, mounting paperwork and essential time lost on the measurement of a game. As one lecturer recalled: we really didn't need figures to prove that we are productive.

Whether PMS can be implemented differently and whether academic work is measurable remains a matter of debate (Molefe, 2012; Marobela and Mawere, 2011; Mapesela and Strydom, 2005). According to Callinicos (2005), neoliberalism in higher education should be seen as part of global capitalism, which promotes productivity and competitive pressure. It is therefore difficult to imagine how PMS can be transformed into an instrument for improving the creativity, motivation and wellbeing of university staff without questioning the subsumption of higher education under the mechanism of a globalized "market". 
IJIKMMENA

2,2

\section{REFERENCES}

Archer, M., Bhaskar, R., Collier, A., Lawson, T. and Norrie, A. (1998), Critical Realism: Essential Readings, Routledge, London.

Armstrong, M. (2009), Handbook of performance Management: An evidence based guide to delivering high performance, $4^{\text {th }}$ edition, Kogan.

Callinicos, A. (2005), Universities in a Neoliberal, World, Bookmarks, London.

Dator, J. (2005), "Universities without 'quality' and quality without 'universities' ", On the Horizon, Vol. 13 Issue 4, pp.199-215.

Harvey, D. (2005), A Brief History of Neoliberalism, Oxford University press, Oxford.

Longenecker, Gioia, D and Sims, H. (1987), Behind the Mask: The Politics of Employee Appraisal, Academy of Management Executive, August pp. 183-193.

Mapesela, M.L.E. and Strydom, F. (2005), Performance management of academic staff in South-African higher education: a developmental research project, OECD Conference "Trends in the management of human resources in higher education”, 25/26 August 2005, Paris, France (http:// www.oecd.org/dataoecd/35/43/35327193.pdf, accessed 28.5.2012)

Marobela, M.N. and Mawere, S. (2011), "Performance Management in the Magistrates Courts of Botswana: gaming and dysfunctionality, the unintended outcomes in public policy reform", African Journal of Business Management, Vol. 5. No. 13, pp. 5311-5318.

Mather, K, Worrall, L. and Seifert, R. (2009), "The changing locus of workplace control in the English further education sector", Employee Relations, Vol. 31 Issue 2, pp. 139-157.

Molefe, G.N. (2012), "Performance measurement model and academic staff: A survey at selected universities in South Africa and abroad", African Journal of Business Management, Vol. 6, No. 15, pp. 5249-5267.

Narsiah, S. (2002), "Neoliberalism and Privatisation in South Africa", GeoJournal, Vol. 57, pp. 3-13.

Osborne, D. and Gaebler, T. (1992), Reinventing Government, AddisonWesley, New York.

Pollitt, C. (1993), Managerialism and the Public Services: cuts or cultural change in the 1990s? Blackwell, Oxford. 
Van Dooren, W. and Thijs, N. (2010), "Paradoxes of improving performance management (systems) in public administration", EIPASCOPE, Vol. 2, pp. 13-18. (http://www.eipa.eu/files/repository/ eipascope/20101022101218_Eipascope_2010_2_Article2.pdf, accessed 27.5.2012)

Employee motivation and academic freedom at the University of Botswana

\section{ABOUT THE AUTHORS}

Dr Motsomi Marobela is a Senior Lecture in Management. He holds a $\mathrm{PhD}$ in Behaviour in Organizations from Lancaster University Management School. Currently, he teaches research methods, industrial relations and public sector management. His research interests are globalization, the labour process and sociology of work.

Dr Kerstin Andrae-Marobela is a molecular cell biologist at the Department of Biological Sciences. Her research focuses on indigenousknowledge (IK)-based science platforms for innovation in relation to human health. She is particularly interested in the interface of research, science \& technology and economic development for communities in Botswana. 